\title{
Sol-gel preparation of silica glass
}

\author{
D KUNDU, G DE, B KARMAKAR, A PATRA and D GANGULI \\ Sol-Gel Laboratory, Central Glass and Ceramic Research Institute, Calcutta 700032, India
}

\begin{abstract}
This paper is a preliminary report on the preparation of silica glass containing very low amount of hydroxyl by the sol-gel processing technique. Gels were' prepared from optimized amounts of tetraethyl orthosilicate, fumed silica and water. Acids and bases in small quantities were added for catalysing hydrolysis and adjusting the $\mathrm{pH}$. Dried gels were heated up to $1400^{\circ} \mathrm{C}$ in various atmospheres to obtain transparent silica glass of the required density and very low $(<5$ ppm) hydroxyl content.
\end{abstract}

Keywords. Silica glass; sol-gel.

\section{Introduction}

High purity silica glass finds applications in semiconductor technology, optical communication and other areas of electronic and related interest (Fanderlik 1991). The sol-gel process of preparing high purity materials has become a potential route because of inherent advantages compared to conventional processing. The high surface area of dried gels results in very high reactivity which, in turn, permits low temperature processing. Thus, unique advantages are offered by this process for the preparation of high-melting special glasses in that the glasses are obtained without melting the starting materials, at temperatures several hundred degrees below the respective melting temperatures. Global efforts (Clasen 1987; Mori et al 1988; Rabinovich 1989; Hench and West 1990) are therefore in progress to develop cost-effective sol-gel technologies for the manufacture of silica glass, which is normally prepared via the melting route at high temperatures.

The present work is a preliminary report of the developments in an on-going project aimed at the preparation of silica glass containing very low amounts of hydroxyl and other impurities by the non-melting, sol-gel technique.

\section{Experimental}

Silica sols were prepared by mixing tetraethyl orthosilicate (TEOS), fumed silica (surface area $180 \mathrm{~m}^{2} \mathrm{~g}^{-1}$ ), double-distilled water and catalytic amounts of $\mathrm{HCl}$. The molar composition of a standard sol was $\mathrm{SiO}_{2}$ from TEOS: $\mathrm{SiO}_{2}$ from fumed silica: $\mathrm{HCl}: \mathrm{H}_{2} \mathrm{O}=1: 0 \cdot 75: 0 \cdot 01: 14$. The $\mathrm{pH}$ of the sol was adjusted to $4 \cdot 2-4 \cdot 7$ by addition of $\mathrm{NH}_{4} \mathrm{OH}$ before casting. The sol and gel preparation processes are shown in the flow diagram (figure 1).

Glasses were prepared from dried gels via heat-treatment at around $1400^{\circ} \mathrm{C}$ in an atmosphere control furnace. During heating, different atmospheres, i.e. vacuum, carbon tetrachloride (with nitrogen as carrier gas), oxygen and helium, were used sequentially at different stages. The physical properties of the gel monoliths were examined by mercury porosimetry (Autoscan 60, Quantachrome) and BET surface area measurement (Sorpty 1750, Carlo Erba). Hydroxyl contents of the glasses were measured by FTIR spectrometry ( 5 PC, Nicolet). 


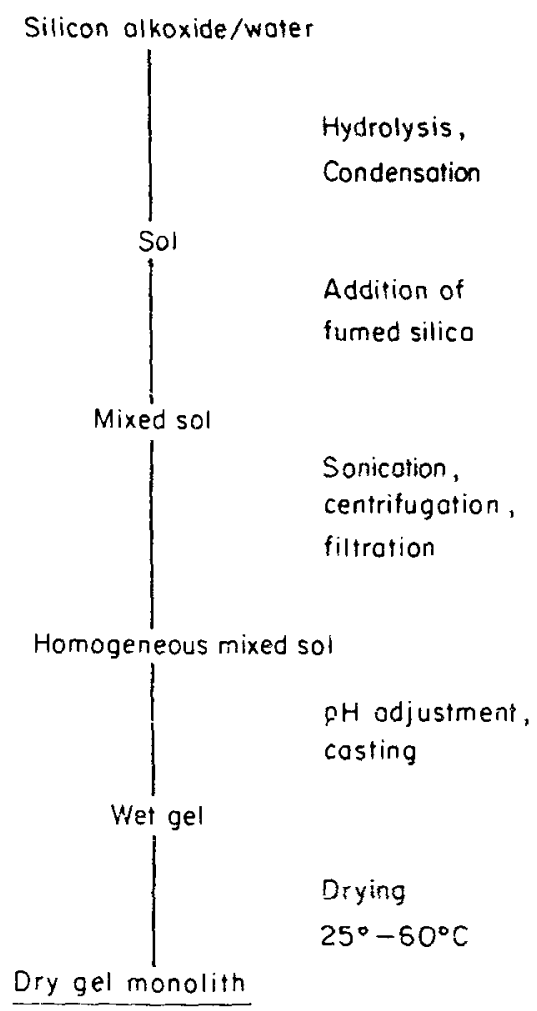

Figure 1. Flow chart for the preparation of monolithic silica gels.

\section{Results and discussion}

For obtaining an optimum workability of the sol (time at hand before gelation), an accurate control of the gelling time of a sol composition is very important. The gelling time is a joint effect of several parameters in sol preparation, e.g. $\mathrm{H}_{2} \mathrm{O} / \mathrm{TEOS}$ ratio, fumed silica/TEOS ratio, $\mathrm{pH}$ of the sol etc. In the present case, an optimum ratio of the major components of the sol was maintained (as under $\S 2$ ), and the gelling time was controlled by a control of the sol $\mathrm{pH}$ before casting. As expected, a monotonic decrease in gelling ime was observed with increasing $\mathrm{pH}$ (figure 2).

The range of $\mathrm{pH}$ selected in this work gave good workability, i.e. 15 to $40 \mathrm{~min}$; lower values of $\mathrm{pH}$ caused unnecessary prolongation of gelling time, while higher values led to almost instantaneous gelation. A pH value of 4.7 was found suitable for most castings.

Figure 3 shows the axial shrinkage behaviour of gel rods during transition from wet to dry condition. Note that the drying time depended upon the size and shape of the wet gel. Bulk density and surface area of the dry gel bodies prepared at $\mathrm{pH}=4.7$ were around $0.8 \mathrm{~g} \mathrm{~cm}^{-3}$ and $360 \mathrm{~m}^{2} \mathrm{~g}^{-1}$ respectively. The average pore diameter exhibited two modes at around 60 and $90 \AA$.

In the sol-gel processing route, the conversion of dried gel bodies to the corresponding transparent glass bypassing the phenomenon of melting, has been explained by the process of viscous sintering (Brinker and Scherer 1990). The 


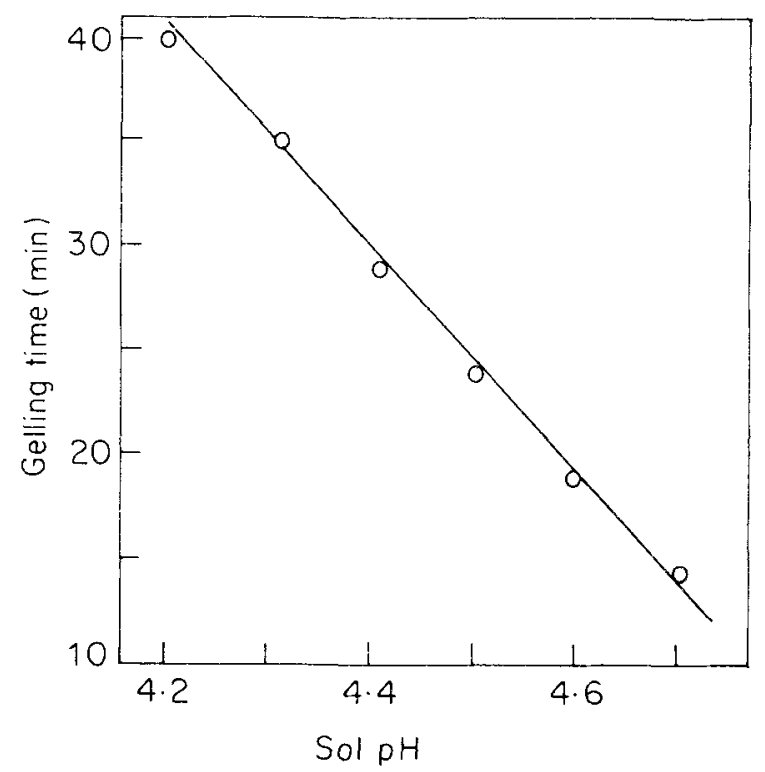

Figure 2. Effect of sol $\mathrm{pH}$ on gelling time.

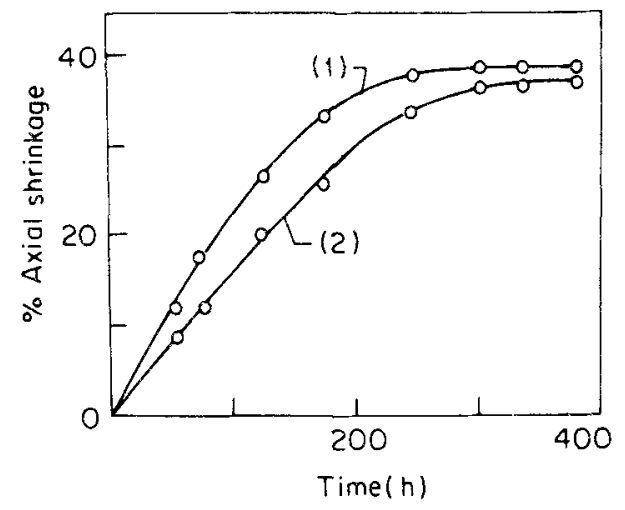

Figure 3. Time dependent axial shrinkage behaviour of gels during drying at $60^{\circ} \mathrm{C}$. Curves 1 and 2 represent the axial shrinkage of gels obtained from 12 and $20 \mathrm{ml}$ sols (taken in polypropylene tubes of height $18 \mathrm{~cm}$ and diameter $1.7 \mathrm{~cm}$ ) respectively.

transformation thus depends on effective elimination of the pores in the gel body and consequent densification via viscous flow of material. One important factor which profoundly influenced densification in the present case was the quantum of tightly bound hydroxyl groups on the surfaces of the pores (Hench and West 1990). Hydroxyl ions on the surface of the gel/glass pores undergo dehydroxylation via $\mathrm{OH}-\mathrm{OH}$ condensation leading to the formation of $\mathrm{H}_{2} \mathrm{O}$ within the temperature range $200-$ $1300^{\circ} \mathrm{C}$, while densification via sintering takes place within $1200-1400^{\circ} \mathrm{C}$. Therefore, densification and dehydroxylation (and formation of $\mathrm{H}_{2} \mathrm{O}$ vapour) occur simultaneously in the temperature range $1200-1300^{\circ} \mathrm{C}$. Thus, if densification is attempted without the removal of a substantial amount of $\mathrm{OH}$ groups from the gel, foaming, bloating and bubble formation will result due to the expansion of $\mathrm{H}_{2} \mathrm{O}$ and other vapours formed and trapped in the closed pores. 
To remove the $\mathrm{OH}$ prior to densification, the gel samples were heat-treated in $\mathrm{CCl}_{4}$ when $\mathrm{OH}^{-}$groups were replaced by $\mathrm{Cl}^{-}$ions. These low-OH gels, when heated in the temperature range $1300-1400^{\circ} \mathrm{C}$ in helium atmosphere, transformed into transparent silica glass. Figure 4 shows a gel body and the corresponding glass after densification. The glass samples were found to have a derisity very close to $2 \cdot 2 \mathrm{~g} \mathrm{~cm}^{-3}$.

The OH content of the glasses was measured by FTIR spectrometry, foilowing BeerLambert law and using an $\varepsilon$ value of $1811 \mathrm{~mol}^{-1} \mathrm{~cm}^{-1}$ (Shelby et al 1982). Figure 5 shows a typical FTIR spectrum of $\mathrm{Si}-\mathrm{OH}$ at $2.73 \mu \mathrm{m}$, on which the quantitative measurement was based, for a fully densified silica glass. The $\mathrm{OH}$ content of such glasses was found to be around $5 \mathrm{ppm}$.

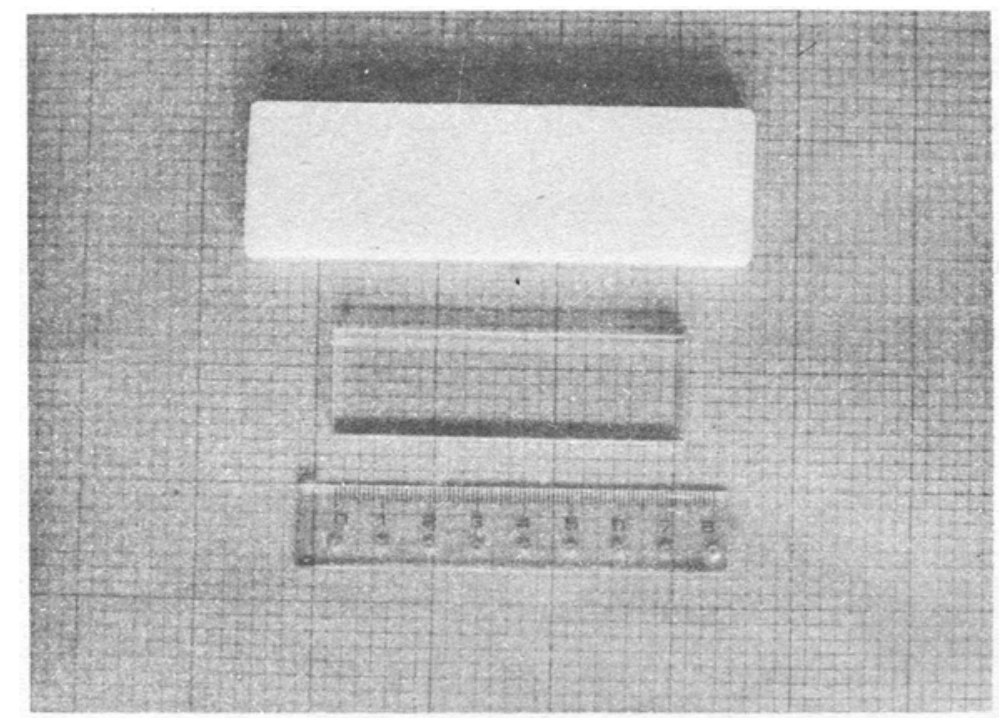

Figure 4. An opaque gel (top) and the corresponding polished glass (bottom) after densification at $1400^{\circ} \mathrm{C}$.

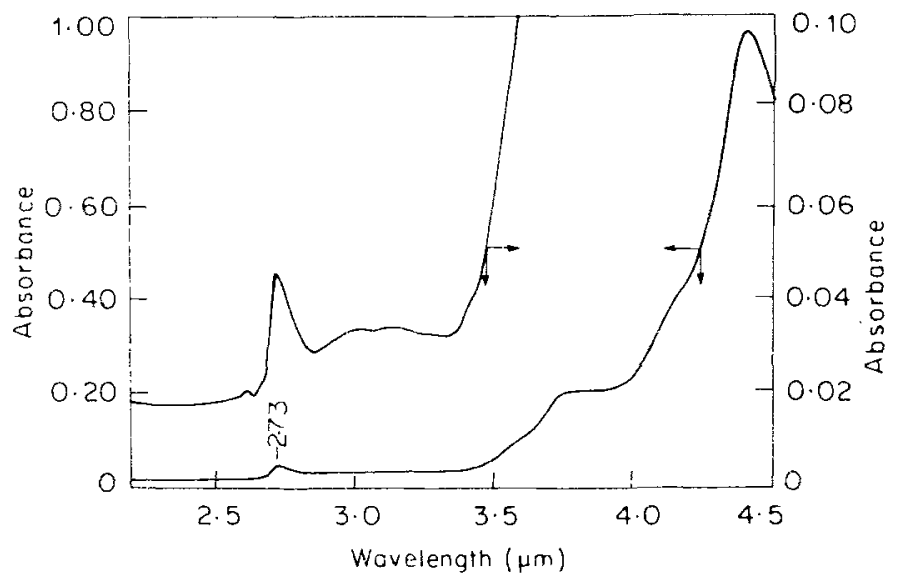

Figure 5. FTIR spectrum of silica glass prepared at $1400^{\circ} \mathrm{C}$ (thickness $2.525 \mathrm{~mm}$ ); $\mathrm{Si}-\mathrm{OH}$ peak at $2.73 \mu \mathrm{m}$ was used for quantitative measurement. 


\section{Acknowledgements}

Experimental help in the characterization of the gels was obtained from S K Das and P K Mondal of the Refractories Division. The authors also thank the Department of Electronics, Government of India, for financial assistance.

\section{References}

Brinker C J and Scherer G W 1990 Sol-gel science (San Diego, USA: Academic Press)

Clasen R 1987 Glastech. Ber. 60125

Fanderlik I (ed.) 1991 Silica glass and its application (Amsterdam: Elsevier)

Hench L L and West J K 1990 Chem. Rev. 9033

Mori T, Toki M, Ikejiri M, Takei M, Aoki M, Uchiyama S and Kanbe S 1988 J. Non-Cryst. Solids 100523

Rabinovich E M 1989 in Sol-gel science and technology (eds) M A Aegerter, M Jafellicie Jr, D F Souza and E D Zanotto (Singapore: World Scientific) pp. 375-401

Shelby J E, Vetco J Jr and Benner R E 1982 J. Am. Ceram. Soc. 60 C-59 